IV Congreso Internacional Estética y Política Poéticas del desacuerdo para una democracia plural 16 y 17 de octubre. Valencia

Doi: http://dx.doi.org/10.4995/CEP4.2019.10538

\title{
Disidencias sexuales, estéticas Museari, procesos críticos en el aula y ritos online mediante el proyecto Arteari
}

\section{Ricard Huerta}

Universitat de València ricard.huerta@uv.es

\begin{abstract}
The potential of the online environment to promote cultural policies and educational innovations is connected with our ability to redefine the relationships between school, museum and university. On the other hand, contemporary art and art education are introducing a social line that has among the struggle for Human Rights. Museari was created involved in these advances in technological order and social balance. Museari is an online museum in which projects are being developed to improve the situation of LGBT groups, coordinating activities through art, history and education. Museari uses cyberspace to create networks between teachers and students, defending diversity. As a museum of contemporary art, Museari presents images and resources that will serve to address issues related to dissenting cultures, offering the teaching group adequate tools. In this same line of work the Arteari project claim from the academic issues that affect the social landscape, influencing respect for sexual diversity. We pay attention to the needs of teachers. We choose to train and inform through sensitization, also activating spaces for reflection. The model combines permanent collection, temporary exhibitions and news, boosting interactivity with the public.
\end{abstract}

Keywords: Art, Education, Museum, Sexual Diversity, Human Rights, Teacher Training.

\begin{abstract}
Resumen
El potencial del entorno online para impulsar políticas culturales e innovaciones educativas está en conexión con nuestra habilidad para redefinir las relaciones entre la escuela, el museo y la universidad. Por su parte, el arte contemporáneo y la educación artística están tomando una deriva social que tiene entre sus frentes más activos la lucha por los derechos humanos. Conscientes de la necesidad de implicarnos en estos avances de orden tecnológico y de equilibrio social, se creó Museari, un museo online en el que se desarrollan proyectos para mejorar la situación de los colectivos LGTB, coordinando actividades a través del arte, la historia y la educación. Museari utiliza el ciberespacio para crear redes entre profesorado y alumnado, defendiendo la diversidad. Como museo de arte contemporáneo presenta imágenes y recursos que servirán para atender cuestiones vinculadas a las culturas disidentes, ofreciendo al colectivo docente herramientas adecuadas. En esta misma línea de trabajo nació el proyecto Arteari, en el que reivindicamos desde lo académico cuestiones que afectan al panorama social, incidiendo en el respeto hacia la diversidad sexual. Atendemos de modo particular las necesidades del colectivo docente. Optamos por formar e informar mediante la sensibilización, activando también espacios de reflexión. El modelo combina colección permanente, exposiciones temporales y noticias, impulsando la interactividad con los públicos.
\end{abstract}

Palabras clave: arte, educación, museo, diversidad sexual, derechos humanos, formación del profesorado. 


\section{Introducción}

Museari pone en tela de juicio el propio concepto de museo. Precisamente ahora que se está debatiendo por parte de ICOM la nueva definición de museo (bloqueo a la propuesta de la comisión por parte de la Asamblea General el 7 de septiembre de 2019) , desentrañamos algunas cuestiones que parecían evidentes: ¿Quién puede crear o tener un museo?, ¿Quién accede al arte contemporáneo? Auscultamos la relación entre el museo y sus opciones educativas, favoreciendo una interacción de carácter interseccional. Apostamos por la investigación, tanto artística como educativa. Mientras las grandes multinacionales de la información y la comunicación compiten por reestructurar las novedades en base a criterios básicamente comerciales y de calado economicista, las voces peculiares nos devuelven el entusiasmo mediante escenarios alternativos y comprometidos con las problemáticas acuciantes. En esta línea de creación de entornos culturales innovadores Museari se convierte en un espacio accesible, peculiar, curioso, de entidad activista, un entorno apto para generar reflexiones estéticas y educativas. Además, Museari atiende a las dudas que surgen entre el colectivo docente cuando se abordan temáticas LGTB en el aula. Nacido por iniciativa de dos profesores universitarios activistas LGTB, parte de un compromiso con la educación, el arte, la historia, los derechos humanos y la coherencia académica (Ordine, 2013).

\section{Avanzando en la lucha contra la homofobia y la transfobia en los entornos educativos}

Entre las posibilidades de expansión y futuro que utilizamos para la educación artística destaca la reivindicación social. Dentro de la vertiente socializadora de la educación en artes se enmarcan los avances en materia de género. Junto con los planteamientos que provienen de los feminismos emergen también las teorías y prácticas del activismo LGTB (Huerta y Alonso-Sanz, 2015). La lucha por los derechos humanos se convierte, de este modo, en un lugar común desde el que implementar tanto las políticas culturales como las innovaciones educativas (Huerta, 2016). Conscientes de la necesidad de implicarnos en estas tentativas que promueven la convivencia y el equilibrio social, hemos creado Museari. Se trata de un museo online desde el que se desarrollamos proyectos pensados para mejorar la situación de los colectivos LGTB. Museari impulsa y coordina actividades participativas. Inspirado en la tradición académica y la cultura del respeto, el proyecto utiliza las posibilidades que ofrece el ciberespacio para coordinar esfuerzos y posibilitar redes entre el profesorado y el alumnado, defendiendo el derecho a la diversidad.

En Museari elaboramos materiales educativos vinculados a la colección permanente y las exposiciones temporales, colaborando con otras instituciones en la programación de actividades, estimulando así un mayor alcance e incidencia entre docentes en el apartado Museari Educa. Es importante que el profesorado cuente con materiales para llevar al aula las temáticas que afectan a los colectivos LGTB. Quienes deseen trabajar las diversidades en clase disponen así de materiales en internet, de fácil acceso, gratuitos, y siempre disponibles. De este modo, el profesorado puede utilizar las obras artísticas expuestas en el histórico del museo, y generar las actividades pensadas para llevarlas a cabo en el aula. Museari es un entorno diverso y participativo. 


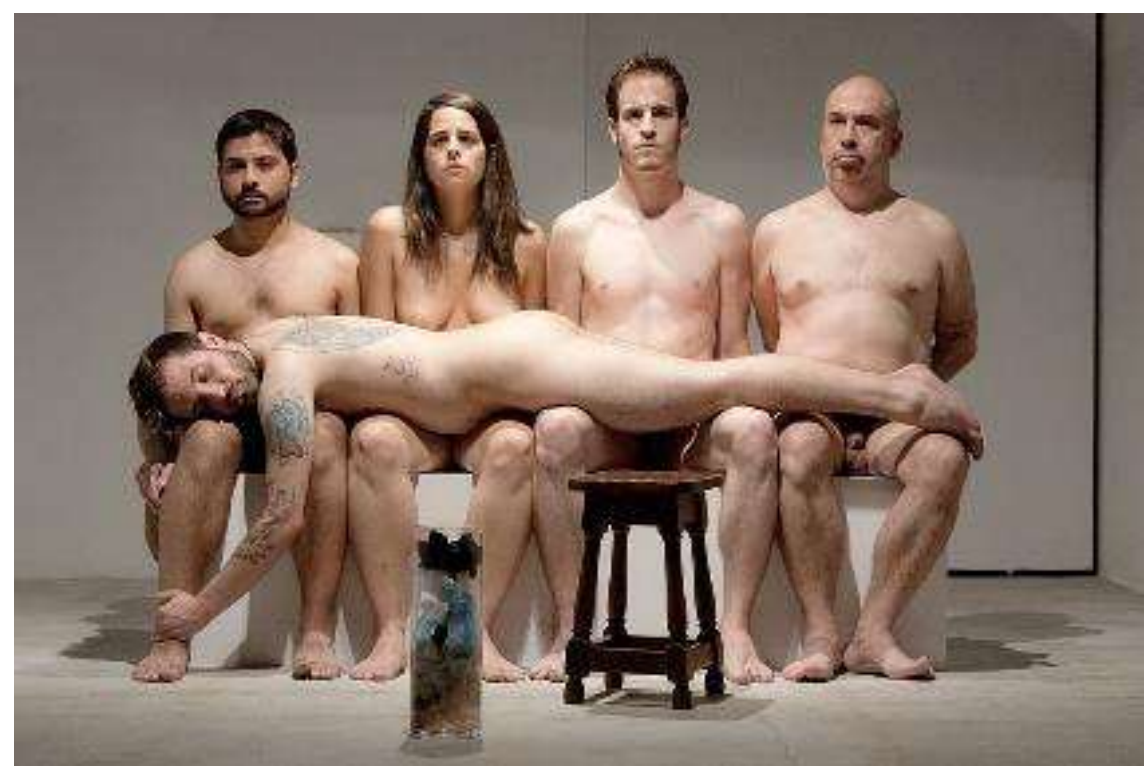

Fuente: Azcona, A. (2015)

Fig. 1 Seropositive. Abel Azcona. Obra expuesta en Museari.

En las últimas décadas venimos asistiendo a una serie de rupturas y tránsitos que están reconfigurando los territorios del arte (Patiño, 2017), de la estética (Laddaga, 2006), de la educación (Sancho, Hernández y Rivera, 2016), y por supuesto de la educación artística (Huerta, 2018). Hemos pasado de un modelo en el que predominaba el rol del artista creador hacia una nueva realidad en la que urge atender el papel de los públicos usuarios y comprometidos. Esto ha provocado una tendencia hacia la reconversión de los intereses. Creemos que sucede algo similar en lo relativo a comportamientos ideológicos y políticos. Las certezas de la modernidad propias del siglo XX nos empujaban hacia polaridades y distanciamientos. Nuestro acercamiento a los usos culturales siempre estuvo muy mediado por las reflexiones semiológicas (Barthes, 1982). Sin embargo, el panorama rizomático ha resquebrajado los postulados anteriores, de manera que los flujos cambiantes del momento actual nos sitúan en incertidumbres líquidas más propias de un cierto malestar permanente. Se trata de un estado donde predomina la levedad, tal y como había preconizado Ítalo Calvino con sus Lecciones Americanas (Calvino, 1995). Deleuze y Guattari insistieron en la volatilidad de los pronósticos, ya que desde las miradas anteriores propias del binarismo moderno únicamente se atendía a la polaridad y la duplicidad: "Ni qué decir tiene que este pensamiento jamás ha entendido la multiplicidad: para llegar a dos, según un método espiritual, necesita presuponer una fuerte unidad principal" (Deleuze y Guattari, 2004: 11). Pese a las tendencias más líquidas en las que estamos instalados, según Zigmut Bauman, lo cierto es que las tensiones continúan, y esto es debido en parte al modelo de economía neoliberal en la que nos encontramos inmersos. También en la vertiente de la comunicación impera lo que Itamar Even-Zohar describió como "polisistemas" (Even-Zohar, 1990). En cualquier caso, las alteridades están impulsando nuevas lecturas del mundo, y tenemos que celebrar el empuje de miradas que provienen de los feminismos, de la diversidad LGTBIQ, de las posiciones afroamericanas, y de todos los pensamientos otros.

\section{Estéticas queer y nuevos escenarios para la disidencia}

Al revisar los espacios de las diversidades LGTBIQ, observamos que una de las voces más rompedoras es sin duda el engranaje queer. El propio concepto queer lo podemos entender como un territorio de tensión donde se dan discursos y prácticas que se posicionan contra las narrativas dominantes, narrativas que son habitualmente de cariz blanco, hetero, cis y monógamo, modelos donde se sitúan personas que han construido su subjetividad a través de un proceso identitario, reconociendo y trabajando sus privilegios. Lo queer supone un total rechazo al régimen normativo en diferentes dimensiones, por ello propone la interseccionalidad de la lucha y la ruptura con toda norma que presione sobre nuestros cuerpos por motivos de clase, raza, género, sexualidad o corporalidad. La transgresión ha sido y sigue siendo la marca identificadora de las otredades. Dentro del espectro LGTB podemos encontrar voces singulares, incluso distantes. 
Estamos asistiendo a una reverberación mediática de la visibilidad de estos colectivos diversos, lo cual enriquece el panorama visual de estas nuevas realidades (Huerta y Alonso-Sanz, 2017). Un ejemplo sencillo que evidencia esta mayor visibilidad sería la profusión del imaginario de la diversidad sexual: se han popularizado elementos gráficos del elenco LGTB como la bandera multicolor o el triángulo rosa, se han instituido manifestaciones como las marchas del Orgullo, y tanto en el cine como en la televisión o en la literatura escrita se prodigan los personajes y las temáticas alusivas. Por otro lado, la mayoría de avances en materia de derechos legales y de progreso social que venimos observando en los logros del colectivo LGTB atienden a unas políticas de igualdad que responden a criterios de visibilidad y mejora de la calidad de vida de las personas. Pero también existen retrocesos espectaculares en países donde se había logrado avanzar.

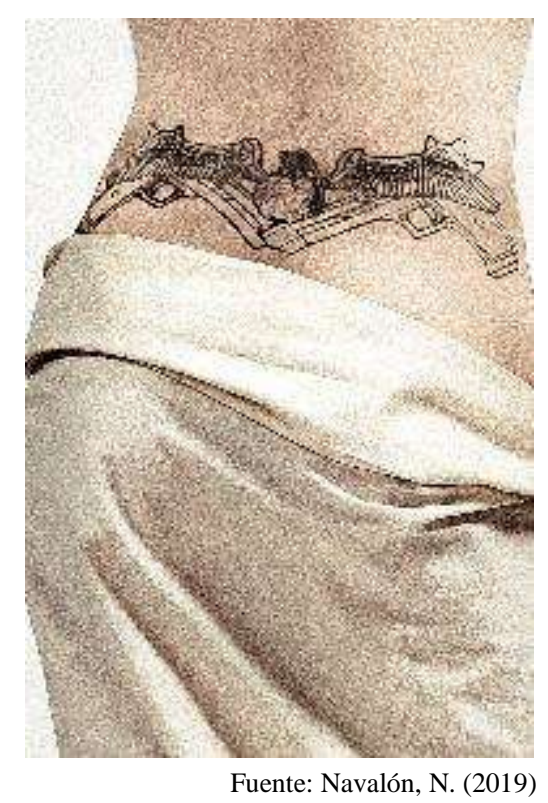

Fig. 2. Serie "No lo llamaban hogar, pero era todo lo que ella tenía”. Natividad Navalón. Obra expuesta en Museari.

En la serie "No lo llamaba hogar, pero era todo lo que ella tenía", la artista Natividad Navalón parte de la metáfora de indigencia, que es en el fondo, una forma de comprender a la mujer, pero sobre todo, una forma de comprendernos a nosotras mismas: "Nos hemos convertido en hijas de la indigencia, náufragas en busca de una isla, esa pequeña conquista del caos. A nosotras nos corresponde la puesta en cuestión de todo discurso, pero somos conscientes de que por mucho que nos desesperemos, ese camino lo estamos recorriendo solas." El derecho al matrimonio de todas las personas es sin duda un logro de la lucha del movimiento LGTB. Este tipo de lucha se ha llevado a cabo de forma paralela las disidencias queer, que siempre gestionan un cierto desapego a los avances legales que emparentan a las personas LGTBIQ con la tradición heteronormativa y heteropatriarcal (Eribon, 2014). Resulta fundamental hablar abiertamente al alumnado de estas cuestiones. El mundo educativo está atendiendo también estas necesidades y urgencias que son propias del nuevo emplazamiento liviano y diverso (Hamlin y Fusaro, 2018). Vamos revisando los papeles del alumnado y el profesorado en el marco de las relaciones académicas (Rolling, 2017).

Investigamos las posibilidades de mejorar los entornos educativos en base a criterios donde no prevalezcan únicamente los intereses económicos, articulando escenarios más generosos e integradores (Raedó y Atrio, 2018). De este modo la investigación educativa se desplaza hacia los intereses de las personas y los colectivos (Panciroli, 2016), por lo que el currículo deja de ser la razón última de las relaciones entre alumnado y profesorado (Huerta y Domínguez, 2015). Ahora nos preocupan más los sentimientos y las emociones, aspectos que hasta hace poco no eran valorados por parte de los responsables educativos. Así damos paso a una gama más amplia de matices (Planella, 2014). El cuerpo, los deseos, las pulsiones y la libertad constituyen elementos fundamentales para gestionar una buena mejora de las condiciones de vida de las personas (Foucault, 2012). Estas nuevas visiones de lo corporal han de resultar familiares al profesorado (Butler, 
2006). Si estamos formando a futuros profesionales de la educación, debemos introducir temáticas que mejoren el panorama de los derechos humanos en materia de diversidad. Nos hemos marcado nuevas direcciones en base a los elementos que atienden a las relaciones de poder. La forma de gestionar estas nuevas visiones corresponde también a los maestros de primaria y a los docentes de secundaria. Todas las iniciativas han de basarse en el respeto y la coherencia. Los hechos personales que nos afectan como profesores también forman parte del currículum que debemos transmitir al futuro profesorado de primaria (Huerta, 2019). En la infancia padecí acoso homofóbico, y a lo largo de mi vida he tenido que combatir constantemente los ataques contra las personas que somos diversas. Reflexiono y me reafirmo en la necesidad de transmitir a mi alumnado estas cuestiones, que tanto sufrimiento provocan a personas inocentes.

\section{Educar en el respeto para transformar los entornos formales e informales}

Las nuevas realidades que ha propiciado el entorno online están replanteando muchas cuestiones que hasta hace bien poco parecían inalterables e inamovibles. Un ejemplo de ello es la propia esencia del concepto de patrimonio y más concretamente la configuración del museo como institución. Atendiendo a la normativa ICOM (International Council of Museums) partimos de la definición de museo como una "institución permanente, sin fines de lucro, al servicio de la sociedad y abierta al público, que adquiere, conserva, estudia, expone y difunde el patrimonio material e inmaterial de la humanidad y su ambiente con fines de estudio, educación y recreo". Esta definición sigue vigente desde que en el Congreso de Viena de 2007 se aprobase por los comisionados de todos los países integrantes. Para obtener una valoración positiva por parte de ICOM, los museos deben atender todos los aspectos referidos: adquisición, conservación, estudio, educación y recreo. Nos interesa reforzar el papel educativo de los museos (Navarro, 2019).

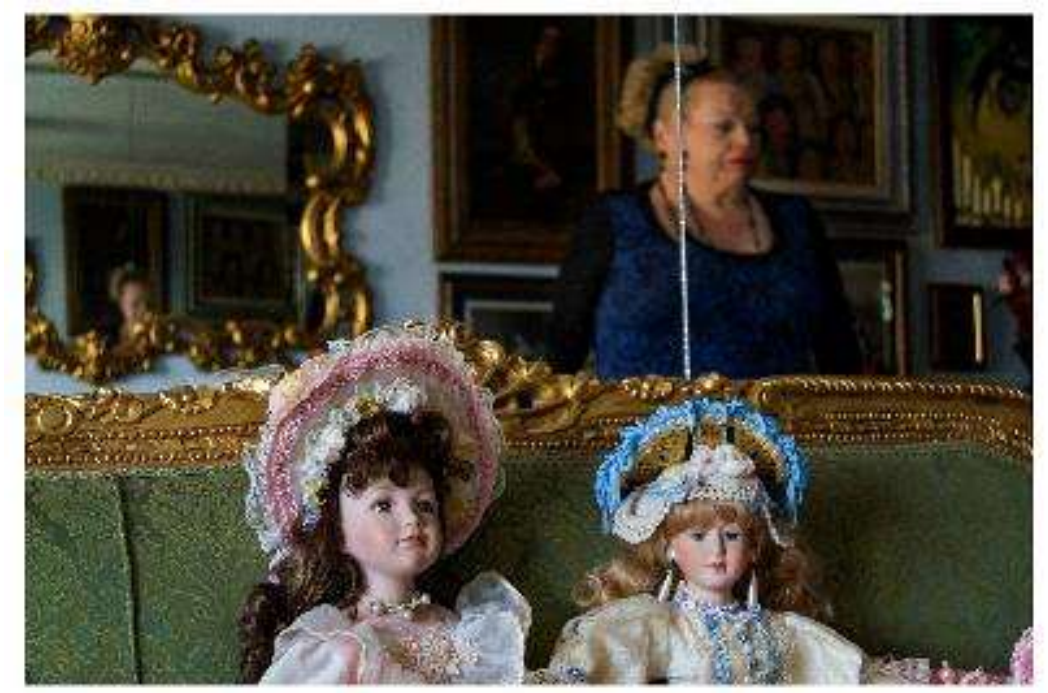

Fuente: Curbelo, D. (2018)

Fig. 3. Memorias Aisladas. Dani Curbelo. Obra expuesta en Museari.

En su trabajo "Memorias Aisladas", Dani Curbelo defiende a las peronas trans de las Islas Canarias, recuperando su tradición, poniendo en valor su valentía durante los años difíciles de la dictadura. Estas reivindicaciones históricas han de estar presentes en los entornos educativos. El museo debe inspirar encuentros como la escuela, una institución aliada del trabajo educativo y de los profesionales de la docencia. En el caso de los museos de arte disponemos, además, de imágenes y recursos que servirán para atender a múltiples cuestiones vinculadas con la cultura y los progresos de la humanidad. Algo similar ocurre con el lenguaje del cine (Huerta, Alonso-Sanz y Ramon, 2019). No perdamos de vista que uno de los elementos más reproducidos en las obras de arte es, precisamente, el cuerpo humano. Y el cuerpo en disputa es el elemento clave de las cuestiones que afectan al deseo, a la mirada y a la representación visual de lo carnal. Estos temas forman parte esencial de nuestras clases de formación del profesorado de primaria, donde analizamos desde el trabajo por 
proyectos cuestiones como: la muerte, el cuerpo, la diversidad, el miedo, la memoria. Si lo observamos como una trayectoria histórica de la mirada, los desnudos masculinos y femeninos que atraviesan la historia del arte y que actualmente inundan el cine, la televisión y los videojuegos, son en realidad una constante que podríamos entender como un motivo visual (Balló, 2000). Recorrer la historia de la representación de San Sebastián en los numerosos ejemplos de los museos del mundo supone entender la mirada del arte hacia el cuerpo humano en diferentes épocas y tradiciones. Incluso analizar aquellos elementos invisibilizados por parte de los museos puede suponer un memorable ejercicio de aproximación a los tabúes tradicionales (Frost, 2007).

Gracias a nuestro interés por la educación en museos, hemos podido revisar los aspectos tradicionales de la relación entre el museo y las opciones educativas, teniendo en cuenta que en la actualidad muchos museos ya no se sustentan en una realidad geográfica, sino que forman parte del entorno online. Se trata de museos que existen en internet como entidades que mantienen su estrategia dentro de los parámetros de la realidad virtual. Estos museos también cumplen con los requisitos del concepto acuñado por ICOM, pero a diferencia de los museos convencionales, no existe un espacio geográfico en el que ubicarlos, sino que optan por ofrecer sus servicios a través de la red (Huerta y Navarro, 2015). Quisiera aclarar aquí que no estamos hablando de las "versiones digitales" de los museos ya existentes, ni tampoco de las aplicaciones en red que algunas instituciones convencionales han adaptado de sus colecciones. Nos referimos a museos que han nacido desde una perspectiva digital y que tienen su actividad básicamente en el entorno virtual. Museari es un museo online que organiza sus activos a partir de la conexión digital con sus visitantes y usuarios.

\section{Conclusiones}

El escenario social y político en el que nos movemos en los países occidentales ha permitido conseguir logros importantes en lo relativo a derechos de grupos minoritarios. Las democracias europeas y americanas están dando muestras palpables de avances en materia legal y asistencial hacia los colectivos LGTB. Somos conscientes de que entre todos estamos consiguiendo que se superen muchos problemas que hasta hace bien poco parecían insalvables. Incluso a nivel cultural se está asumiendo el importante papel del colectivo en las parcelas de los saberes creativos (LORD y MEYER, 2013). Y sin embargo, no podemos perder de vista que lo conseguido puede que no se vaya a mantener siempre. Es por ello que la lucha por los derechos humanos debe continuar firme, y no podemos confiar en la perennidad de los logros, ya que constantemente están en peligro los avances alcanzados (Calvelhe Panizo, 2019).

Tanto para el tratamiento de aspectos graves como es el ciberbullying (acoso digital) como para repensar las posibilidades del uso educativo de las imágenes en internet, conviene plantearse hasta qué punto somos capaces de elaborar un lenguaje adecuado y pertinente al utilizar los entornos online en nuestras tareas cotidianas. Y es que para comprender la forma de interacción entre la cultura y la visión, no solamente debemos entender cómo funciona la vista, sino también desarrollar una mirada cultural, de manera que aprovechemos las respuestas diseñadas dese el cerebro y por supuesto las que llegan a él de manera no deseada. Nos relacionamos cada vez más con experiencias visuales ya construidas, lo que provoca que la distinción entre imagen y realidad se haga progresivamente más difusa. A tal efecto, desde los Estudios Visuales se intenta comprender e investigar sobre la cultura visual, ya que éstos no se ocupan únicamente de los objetos y artefactos visuales, sino que también abordan las relaciones y prácticas de subjetivación que generan.

\section{Referencias}

BALló, J. (2000). Imatges del silenci. Els motius visuals al cinema. Barcelona: Empúries.

BARTHES, R. (1982) Lo obvio y lo obtuso: Imágenes, gestos, voces. Barcelona: Paidós.

ButLER, J. (2006). Deshacer el género. Barcelona: Paidós.

Calvelhe Panizo, L. (2019). Adolescentes gays en la era digital: orientaciones para la educación. Alteridad, v. 14, n. 1, p. 65-75. DOI: https://doi.org/10.17163.alt.v14n1.2019.05

CAlvino, I. (1995). Seis propuestas para el próximo milenio. Madrid: Siruela. 
Rodrigues Da Costa, F. (2019). Ensino/Aprendizagem das Artes Visuais na América Latina: colonialidade cultural e emocional aliada a questões LGBT. 197 Revista GEARTE, 6 (2), 197-246. DOI: $\underline{\text { http://dx.doi.org/10.22456/2357-9854.92908 }}$

Deleuze, G. y GuATtari, F. (2004). Mil mesetas. Capitalismo y esquizofrenia. Valencia: Pre-Textos.

ERIBON, D. (2014). La societé comme verdict. París: Flammarion.

Even-Zohar, I. (1990). Polisystem Theory. Poetics Today, v. 11, n. 1, p. 9-26. 1990.

FouCAult, M. (2012). Vigilar y castigar. Nacimiento de la prisión. México: Siglo XXI Editores.

Frost, S. (2007). The Warren Cup: Highlighting Hidden Histories. International Journal of Art and Design Education, v. 26, n. 1, p. 63-72. 2007.

Hamlin, J.; FusARo, J. (2018). Contemporary Strategies for Creative and Critical Teaching in the 21st Century. Art Education, v. 71 , n. 2, p. 8-15. DOI: https://doi.org/ $10.1080 / 00043125.2018 .1414529$

HuERTA, R. (2016). Transeducar. Arte, docencia y derechos lgtb. Barcelona: Egales.

HUERTA, R. (2018). "Hurgar en los miedos al cuerpo. La formación en artes de futuras maestras interpelando la obra de mujeres artistas". Arteterapia, 13, 69-84. doi: http://dx.doi.org/10.5209/ARTE.60132

HUERTA, R. (2019). Arte para primaria. Barcelona: UOC.

HuERTA, R. Y Alonso-SAnZ, A. [eds.] (2015). Educación artística y diversidad sexual. Valencia: PUV.

Huerta, R. Y AlONSO-SANZ, A. [eds.] (2017). Entornos informales para educar en artes. Valencia: PUV.

Huerta, R., Alonso-SAnZ, A. Y Ramon, R. (2019). De película. Cine para educar en diversidad. Valencia: Tirant lo Blanch.

HuERTA, R. Y DOMíNGUEZ, R. (2015). "Investigar sobre los entornos educativos y abordar la problemática situación de la educación artística en secundaria”. EARI. Educación Artística Revista de Investigación, 6, 10-18. DOI: http://dx.doi.org/10.7203/eari.6.6887

Huerta, R. Y NAvarro, G. (2015). Museari. An online Museum about Sexual Diversity. Museum Education and Accessibility. Bridging the Gaps, Washington: CECA-ICOM, 145-149.

LADDAGA, R. (2006). Estética de la emergencia. Buenos Aires: Adriana Hidalgo.

LORD, C. Y MEYER, R. (2013). Art \& Queer Culture. London: Phaidon. 2013.

NAVARRo, G. (2019). Museari Queer Art: el projecte Arteari en las Naves. València: Espai d'Art Fotogràfic. Accesible en

https://www.museari.com/wp-content/uploads/pdf/CatalogoMuseariQueerArt.pdf

ORDINE, N. (2013). La utilidad de lo inútil. Barcelona: Acantilado.

PANCIROLI, CH. (2016). "Los bienes culturales como patrimonio educativo”. EARI Educación Artística Revista de Investigación, 7, 8699. doi: https://doi.org/10.7203/eari.7.8158

PAtiño, A. (2017) Todas las pantallas encendidas. Hacia una resistencia creativa de la mirada. Madrid: Fórcola. 2017.

Planella, J. (2014). El oficio de educar. Barcelona: UOC.

RAEDÓ, J. Y ATRIO, S. (2018). “Arquitectura inclusiva y su utilización como instrumento socializador en educación”. Tarbiya, Revista de Investigación e Innovación Educativa, 46, 41-54.

Rolling, J. H. (2017). Art + Design Practice as Global Positioning System. Art Education, v. 70, n. 6, p. 4-6. https://doi.org/10.1080/00043125.2017.1361756

SANCHO, J. M.; HERNÁNDEZ, F.; RiVERA, P. (2016). Visualidades contemporáneas, ciudadanía y sabiduría digital: Afrontar las posibilidades sin eludir las tensiones. Relatec Revista Latinoamericana de Tecnología Educativa, v. 15, n. 2. https://doi.org/10.17398/1695-288X.15.2.25 